\title{
Definition of microclimatic conditions in a karst cavity: Rull Cave (Alicante, Spain).
}

\section{Pla (1,2*); J.J. Galiana-Merino (3); J. Cuevas-González (1); J.M. Andréu (1); J.C. Cañaveras (1,2); M.A. García-del-Cura (2); S. Cuezva (1); A. Fernández-Cortés (4); E. García-Antón (4); S. Sánchez-Moral (4); D. Benavente $(1,2)$}

(1) Dpto. Ciencias de la Tierra y del Medio Ambiente. Universidad de Alicante. Campus San Vicente del Raspeig s/n. 03690 San Vicente del Raspeig (Alicante).

(2) Laboratorio de Petrología Aplicada. Unidad Asociada CSIC-Universidad de Alicante. Campus San Vicente del Raspeig s/n. 03690 San Vicente del Raspeig (Alicante).

(3) Dpto. Física, Ingeniería de Sistemas y Teoría de la Señal, Universidad de Alicante, 03690-Alicante, Spain,

(4) Museo Nacional de Ciencias Naturales (CSIC). José Gutiérrez Abascal, 2. 28006 Madrid.

*Corresponding author: $\underline{\text { c.pla@,ua.es }}$

\begin{abstract}
Rull cave (Alicante, SE Spain) is a shallow karstic cavity located in metrethick beds of Miocene limestone conglomerate and overlain by soil with little profile development. A microenvironmental monitoring system was installed in order to record the exchange between the cave and the external atmosphere. Data were collected every 15 minutes over a period of 14 months (from 22/11/2012 to 13/01/2014). Both radon and $\mathrm{CO}_{2}$ concentration values changed over the course of the annual cycle and were strongly controlled by the difference in air temperature between the exterior and the cave atmosphere. Wavelet transform was applied to the data to determine the influence of visitors on the environmental parameters controlling the cave's microclimate.
\end{abstract}

Keywords: karst, gas exchange, microclimatic measures, Rull cave. 


\section{Introduction}

Underground cavities have been widely studied in order to assess the behaviours, patterns and trends of current microclimatic factors (FernandezCortes et al. 2009, Fernandez-Cortes et al. 2013, among others). Fluctuations in temperature, relative humidity or barometric pressure enable determination of annual cycles, which can then be studied in detail to understand underground systems. These fluctuations govern the exchange of gases such as $\mathrm{CO}_{2}$ and ${ }^{222} \mathrm{Rn}$ through the soil membrane between underground and environmental atmospheres, and determine the outgassing and isolation stages of a subterranean atmosphere (Cuezva et al. 2011). The dynamics of these processes can be studied by applying new techniques such as wavelet analysis (Galiana-Merino et al. 2013) to time series.

The aim of this study is to understand the relationship between measured microclimatic parameters and the behaviour of trace gases $\left(\mathrm{CO}_{2}\right.$ and $\left.{ }^{222} \mathrm{Rn}\right)$ by analysing variations inside and outside Rull cave, and to quantify the influence of visitors. Wavelet analysis is applied to data in order to determine the relationships prevailing between factors. A microenvironmental system was installed inside the cave to obtain sufficient information about climate parameters and their influence on the natural dynamics of the underground system in relation to outside environmental conditions.

\section{Field site description}

Rull cave ( $\left.38^{\circ} 48^{\prime} 40^{\prime \prime} \mathrm{N} ; 0^{\circ} 10^{\prime} 38^{\prime \prime} \mathrm{W}\right)$ is located in the north eastern sector of Alicante province, on the Spanish Mediterranean coast (30 km from the coast line). The cave is located in the Vall d'Ebo basin, which originated during the late Miocene in response to compressive dynamics affecting 
underlying Cretaceous limestones. This basin was filled by massive series of limestone conglomerates deposited on top of massive clayey marls (Middle Miocene). Rull cave is located in these series of massive conglomerates characterised by considerable textural and petrophysical complexity (De Carvalho et al. 2013). The overlying soil has little profile development with few horizons. Both the fracture system and the mineral composition of the host conglomerates determine the infiltration process of meteoric waters and the exchange of gases. The cavity presents an almost rounded shape, and comprises a total area of $1535 \mathrm{~m}^{2}$. The ceiling reaches a maximum height of 20 metres in the central chamber, and the relative thickness of the overlying host rock varies from 9.3 to 22.3 metres depending on the point selected. The study area is characterised by a thermoMediterranean sub-humid climate (Rivas-Martinez 1984). Inside the cave, calcite speleothems such as stalactites, columns, curtains or crusts are common, and fallen blocks of different sizes are present due to old ceiling collapses. Currently, the cavity has a single entrance shut by a door. Rull cave is a tourist cavity, which has been equipped to receive visitors (during the period studied, Rull cave received an average of 40 people a day), and spotlights and concrete corridors have been installed to allow people to move around easily when visiting the cave.

\section{Methodology}

A microenvironmental monitoring system was installed to record microclimatic data on cave air. The system consisted of one complete station with a data logger (dataTaker DT50, Grant Instruments Ltd., Cambridge, UK) and a set of sensors. Data were recorded at fifteen minute intervals. Air temperature and relative humidity were measured by a HygroClip S3 sensor (Pt100 1/10 DIN temperature sensor and a Rotronic humidity sen- 
sor). Atmospheric pressure was measured with a silicon capacitive sensor (Vaisala BAROCAP). A Ventostat 8002 sensor (Telaire, USA) was used to measure $\mathrm{CO}_{2}$ concentrations, while radon concentrations were determined with a Radim 5 Monitor. Three extra data loggers (HOBO Pro v2 Temp/RH Data Loggers - U23 Family) were installed at different points in the cavity. Outside the cave, a weather station with an independent data logger (HOBO Onset, USA) recorded air temperature, relative humidity, rainfall and wind (speed and direction) values every fifteen minutes. An analysis of the recorded measurements was carried out to determine the prevailing patterns in Rull Cave. In addition, analysis using the software package, Environmental Wavelet Tool (Galiana-Merino et al. 2014), which facilitates wavelet analysis and filtering, cross-correlation, entropy of curves or spline analyses was applied to the obtained data.

\section{Prevailing microclimatic conditions}

The microclimatic records obtained over a period of 14 months (November 2012 - January 2014) are shown in Fig. 1. Rull cave presented high thermo-hygrometric stability throughout the annual cycle. Recorded values of inside temperatures revealed an average value of $15.89^{\circ} \mathrm{C}$. Temperature oscillations were $\pm 1.14^{\circ} \mathrm{C}$. Relative humidity inside the cave was always higher than 95\%; thus, the cave remained under a state of saturation. The average $\mathrm{CO}_{2}$ concentration was $1927 \mathrm{ppm}$, although values in excess of $4000 \mathrm{ppm}$ were recorded when the outdoor temperature was higher than the cave air temperature. Radon concentration showed a similar behaviour; while minimum values were detected from November to March, higher values were reached in summer. The average ${ }^{222} \mathrm{Rn}$ concentration inside Rull cave was $1520 \mathrm{~Bq} \mathrm{~m}^{-3}$, although values reached nearly $4000 \mathrm{~Bq} \mathrm{~m}^{-3}$. 


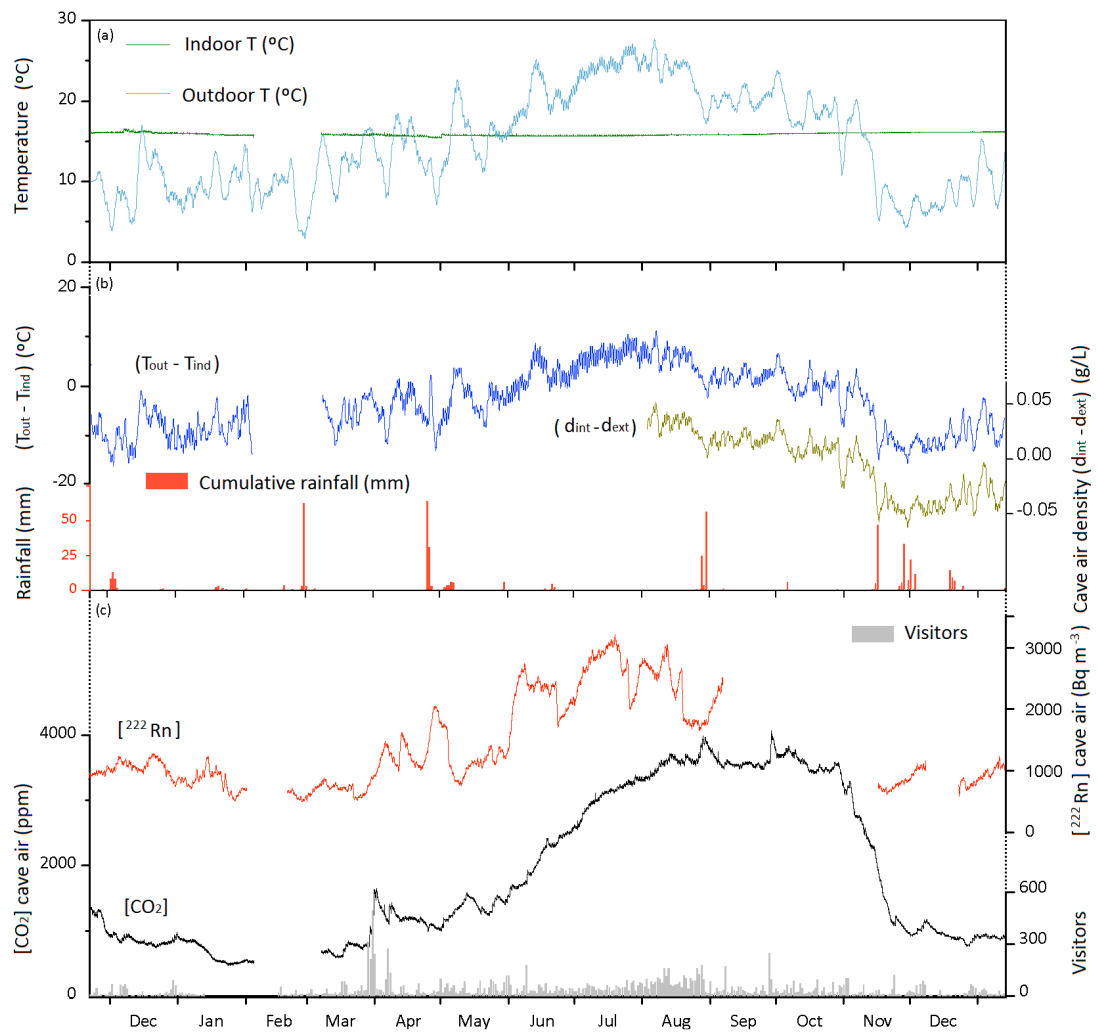

Fig. 1. Time series of the main environmental parameters recorded in Rull Cave (November 2012 - January 2014). (a) Evolution of indoor and outdoor air temperature. (b) Rainfall (absolute daily values), air temperature difference $\left(T_{\text {out }} T_{\text {ind }}\right.$ ) and air density difference $\left(d_{\text {int }}-d_{\text {ext }}\right)$. (c) Carbon dioxide and radon content of the cave air. Visitors, expressed as absolute daily values.

\section{Discussion}

Cave ventilation was strongly dependent on relationships between indoor and outdoor temperatures (Fig. 1). Density differences between the cave and the outside air were primarily responsible for the isolation or outgassing state of the cavity (García-Antón et al. 2014). Furthermore, relative humidity, barometric pressure, cave geometry and the influence of visitors were also significant factors. In winter, ventilation was predominantly driven by air density differences between the cave and the external atmos- 
phere, and air renewal processes maintained radon and $\mathrm{CO}_{2}$ levels below the average annual concentration. In contrast, from May to November, temperatures inside the cave remained below the external temperature; the cave functioned as a trap for cold air and as a net $\mathrm{CO}_{2}$ reservoir. In general, the ${ }^{222} \mathrm{Rn}$ baseline followed the same pattern as that observed for $\mathrm{CO}_{2}$. Throughout the entire cycle, temperature difference and $\mathrm{CO}_{2}$ concentration were totally dependent (Fig. 1).

As Rull cave is a tourist cavity, visitors exert an important influence on the microclimatic conditions inside the cave. In order to enhance detection of this influence, the raw $\mathrm{CO}_{2}$ signal was filtered by applying Discrete Wavelet Transform (DWT). The presence of visitors directly affected short-term $\mathrm{CO}_{2}$ concentrations, subsequently buffered by natural dynamics. When applying DWT, high frequency events (such as visitors) can be clearly distinguished from the signal's natural trend (corresponding to low frequency events). Thus, the influence of visitors can be eliminated and the continuous trend of the signal highlighted. From March $28^{\text {th }}$ to April $9^{\text {th }} 2013$, 1,928 people visited the cavity, and the $\mathrm{CO}_{2}$ signal was studied over this period (Fig. 2). Those days with maximum visitors could be clearly identified in the high frequency component of the $\mathrm{CO}_{2}$ concentration. From $29 / 03$ to $1 / 04$, more than 200 people a day visited the cave. The high frequency signal extracted from measured $\mathrm{CO}_{2}$ concentrations revealed, for instance, an increase of nearly $200 \mathrm{ppm}$ in comparison with the natural trend of raw records on March $31^{\text {st }}$, when 492 people entered the cave. The disturbance in $\mathrm{CO}_{2}$ concentrations caused by visitors was clearly enhanced when both components of the original signal were separated. The number of visitors was directly proportional to the increase in $\mathrm{CO}_{2}$ concentration. 


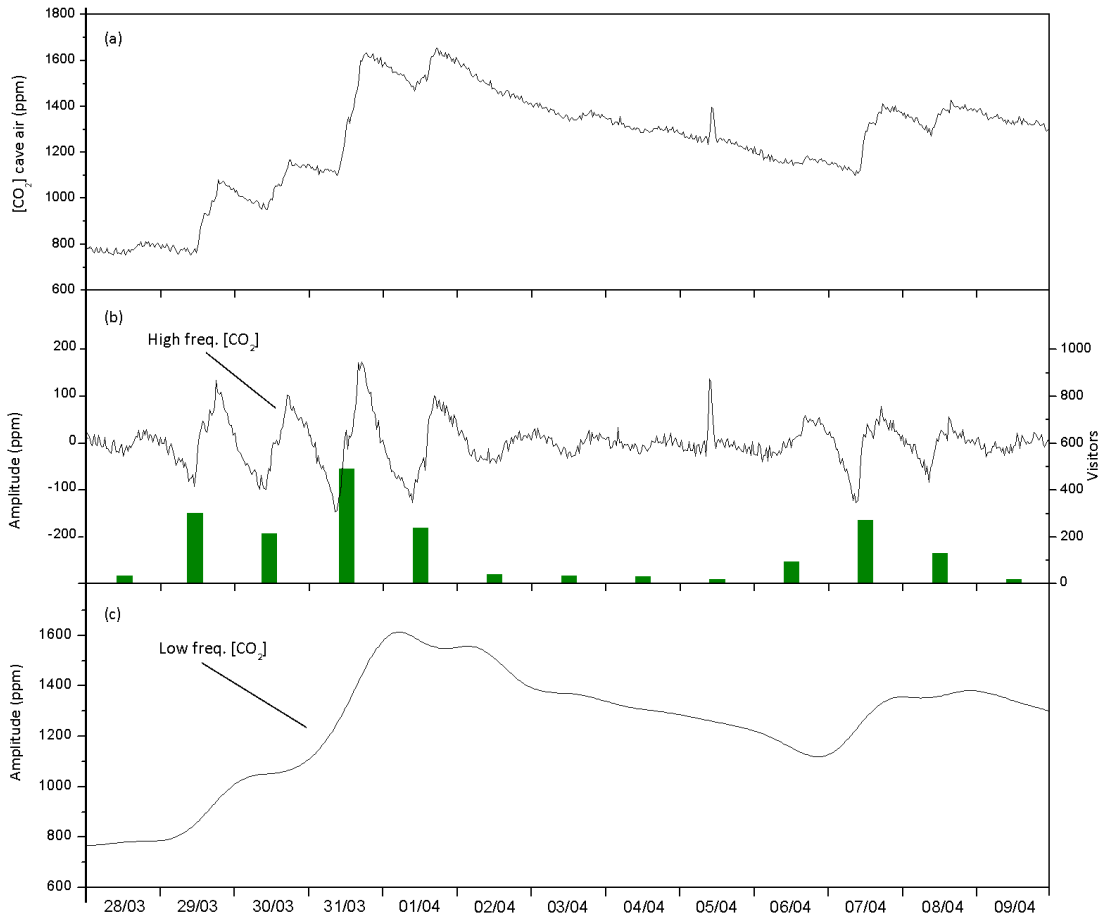

Fig. 2. (a) $\left[\mathrm{CO}_{2}\right]$ raw signal (March $28^{\text {th }}-$ April $4^{\text {th }}$ 2013). (b) High frequency component of $\left[\mathrm{CO}_{2}\right]$ raw signal. (c) Low frequency component of $\left[\mathrm{CO}_{2}\right]$ raw signal. Filtered signals (b and c) are obtained by applying DWT using 5 and Daubechies 10 as scale and mother wavelet filter, respectively.

\section{Conclusions}

The seasonal pattern of trace gases in Rull cave is related to cave ventilation and gas exchange with outside air, mainly controlled by meteorological factors. The main parameters governing the cave's microclimate are differences between outdoor and indoor air temperatures and densities, among others. Furthermore, in tourist caves such as Rull, the presence of visitors exerts a direct, short-term influence on $\mathrm{CO}_{2}$ concentrations. Wavelet analysis has proved a useful tool for analysing and quantifying the disturbance caused by people. The advantages of wavelet analyses applied to 
microclimatic time series has recently been demonstrated. By implementing wavelet transform, a signal can be filtered and divided into different frequency components. Thus, the continuous trend of the signal can be clearly distinguished from high frequency events, providing an extremely useful insight into the relationships between microclimatic parameters and trace gas concentrations in underground systems.

\section{Acknowledgments}

This research was financed by the Spanish Ministry of Science and Innovation (CGL2011-25162). A pre-doctoral research fellowship was awarded to C. Pla for this project.

\section{References}

Cuezva S, Fernandez-Cortes A, Benavente D, Serrano-Ortiz P, Kowalski A.S, Sanchez-Moral S (2011) Short-term $\mathrm{CO}_{2}(\mathrm{~g})$ exchange between a shallow karstic cavity and the external atmosphere during summer: Role of the surface soil layer. Atmospheric Environment $45,1418-1427$.

De Carvalho L, Pla C, Galvañ S, Cuevas-Gonzalez J, Andréu JM, Cañaveras JC, Benavente D (2013) Caracterización Petrográfica y Petrofísica de la Roca Encajante de la Cueva del Rull (Vall d'Ebo, Alicante). Macla 17, p. 39-40.

Fernandez-Cortes A, Sanchez-Moral S, Cuezva S, Cañaveras JC, Abella R (2009) Annual and transient signatures of gas exchange and transport in the Castanar de Ibor cave (Spain). International Journal of Speleology 38(2):153-162.

Fernandez-Cortes A, Sanchez-Moral S, Cuezva S, Benavente D, Abella R (2011) Characterization of trace gases' fluctuations on a 'low energy' cave (Castañar de Íbor, Spain) using techniques of entropy of curves. International. Journal of Climatology 31(1): 127-143.

Galiana-Merino J, Pla C, Fernandez-Cortes A, Cuezva S, Ortiz J, Benavente D (2014) EnvironmentalWaveletTool: Continuous and Discrete Wavelet Analysis and Filtering for environmental time series. Computer Physics Communications, in press.

Garcia-Anton E, Cuezva S, Fernandez-Cortes A, Benavente D, Sanchez-Moral S (2014) Main drivers of diffusive and advective processes of $\mathrm{CO} 2$-gas exchange between a shallow vadose zone and the atmosphere. International Journal of Greenhouse Gas Control 21: 113 $-129$.

Rivas-Martínez S (1984) Pisos bioclimáticos de España. Lazaroa 5: 33-43. 